\title{
Posicionamento logístico com base nas estratégias de produção em micro-organizações familiares: um estudo de caso no setor têxtil
}

\author{
Thiago Duarte Pimentel ${ }^{1}$ \\ Alexandre de Pádua Carrieri ${ }^{2}$ \\ Alfredo Rodrigues Leite da Silva ${ }^{3}$
}

\section{Resumo}

No presente estudo são analisadas as estratégias de posicionamento logístico, enfatizando aquelas relativas à produção e gestão de operações em microorganizações familiares. Com esse intuito realizou-se uma revisão sobre posicionamento logístico, estratégias de produção e operações para fundamentar o caso de uma organização familiar inserida no contexto da Feira de Artes, Artesanato e Produtores de Variedades de Belo Horizonte/MG, conhecida popularmente como Feira Hippie. A pesquisa qualitativa baseou-se na pesquisaação visando identificar, junto ao gestor familiar, as estratégias de posicionamento logístico, de produção e gestão de operações adotadas face ao seu contexto produtivo. Observou-se como a micro-organização familiar em questão adota estratégias internas (tácitas/emergentes) e externas (desenvolvimento de redes sociais), que lhe garantem viabilidade econômica, embora parte desta possa ser atribuída à exteriorização de seus custos aos fornecedores e ao ambiente organizacional.

Palavras-chave: Posicionamento logístico. Estratégias de produção e operação. Pesquisa-ação. Organizações familiares.

\section{Introdução}

Este artigo tem como objetivo descrever e analisar a estratégia de posicionamento logístico, enfatizando as decisões relativas às estratégias de

\footnotetext{
${ }^{1}$ Mestre em Administração pelo CEPEAD/UFMG (2008) e doutorando em Administração pelo PPGAD/UFLA (2009). Endereço: Departamento de Administração da Universidade Federal de Lavras (DAE/UFLA), Campus Universitário, CEP 37200-000 - Lavras, MG - Brasil - Caixa-Postal: 37. E-mail: thiagodpimentel@gmail.com.

${ }^{2}$ Doutor em Administração pelo CEPEAD/UFMG (2001). Professor Adjunto da UFMG/Face/Cad/Cepead. Universidade Federal de Minas Gerais. Endereço: Av Antonio Carlos, 6627, Pampulha,31270-901 - Belo Horizonte, MG - Brasil. E-mail: alexandre@cepead.face.ufmg.br. ${ }^{3}$ Doutor em Administração pelo CEPEAD/UFMG (2007) e mestre em Administração pela UFES (2003). Professor da FUCAPE Business School. Endereço: Fundação Instituto Capixaba de Pesquisa em Contabilidade, Economia e Finanças, Av. Fernando Ferrari, 1358, Goiabeiras $29075-010$ - Vitoria, ES - Brasil - Caixa-Postal: 30170120. E-mail: alfredosilva@fucape.br. Artigo recebido em: 11/02/2008. Aceito em: 17/12/2008. Membro do Corpo Editorial Científico responsável pelo processo editorial: Rolando Juan Soliz Estrada.
} 
produção e gestão de operações, em pequenas empresas familiares. Para tanto, realizou-se um estudo de uma pequena organização familiar inserida no contexto da Feira de Artes, Artesanato e Produtores de Variedades de Belo Horizonte, conhecida popularmente como Feira Hippie.

A premissa subjacente a este trabalho é a de que os conceitos de gerenciamento da cadeia de produção, posicionamento logístico, gestão de estratégias de produção e gestão de operações têm sido muito utilizados apenas no tocante às empresas de grande porte, havendo, portanto, uma lacuna de aplicação desses conceitos e de estudos sobre a sua aplicação em micro e pequenas organizações.

Este estudo se justifica devido a uma série de razões, dentre as quais três podem ser destacadas como mais relevantes. A primeira delas refere-se ao fato de que uma breve análise sobre os artigos de produção e logística publicados nos últimos anos, por exemplo, nos anais do ENANPAD (2005), revelou uma alta concentração de estudos focados em grandes empresas, muitas vezes de empresas estrangeiras e/ou multinacionais. Contudo, essas análises, apesar de serem importantes para a ampliação e consolidação de estudos da área, acabam deixando de lado as questões referentes aos processos logísticos das micro e pequenas organizações. Um problema dessa restrição é que os estudos que refletem o estado da arte da produção acadêmica sobre logística, por não se preocupar também com as micro e pequenas organizações, tenderiam a desprezar uma importante parte das empresas que refletem a realidade brasileira, já que de acordo com Avelar (1998), cerca de $80 \%$ das empresas são micro e pequenas e de cunho familiar.

Outra questão relevante consiste em conhecer como os conceitos de logística desenvolvidos a partir de estudos de grandes organizações exprimem seu potencial explicativo: a partir da perspectiva das micro e pequenas organizações; verificando até que ponto há convergências e divergências entre esses dois tipos de empresas e se seria necessário alguma adaptação; ou ainda, se a singularidade das micro-organizações (familiares ou não) exige o desenvolvimento de conceitos específicos, dentre outras questões.

Por fim, um terceiro elemento que justifica e, de certa forma, legitima este estudo consiste em ver, na sua aplicação prática do cotidiano, como as micro e pequenas organizações estabelecem o seu posicionamento logístico, e quais as estratégias de produção e gestão de operações são adotadas. Isso dentro de um contexto atual cada vez mais dinâmico e competitivo que exige das micro e pequenas organizações uma capacidade de adaptação a fim de 
ajustar e se manter no mercado. Diante do fenômeno da globalização dos mercados, e atuando em ambientes cada vez mais competitivos, as organizações, inclusive as micro e pequenas empresas, têm procurado adotar e desenvolver novas práticas gerenciais e tecnológicas visando apoiar o seu processo decisório.

Considerando essas questões, o presente trabalho buscou identificar, descrever e analisar por meio de um estudo de caso, baseado na metodologia qualitativa de pesquisa e no método da pesquisa-ação junto ao gestor familiar, quais as estratégias de produção e de gestão de operações adotadas por ele para viabilizar o posicionamento logístico de sua produção. Os resultados apresentados mostram as características específicas do posicionamento logístico da empresa estudada, a ênfase em determinados aspectos da política de produção e a tentativa de flexibilização do processo produtivo.

O presente trabalho está estruturado em cinco partes. A primeira corresponde a esta introdução, que fornece um panorama sobre o artigo, sua natureza e objetivos. A segunda seção traz uma breve revisão teórica sobre posicionamento logístico, estratégias de produção e gestão de operações. Já na terceira seção, apresenta-se a metodologia utilizada neste estudo, enfatizando o método de pesquisa-ação. A quarta parte corresponde à análise propriamente dita, onde se evidenciam as características do posicionamento logístico da empresa estudada, suas principais estratégias de gestão da produção e de operações, bem como a sua influência sobre o resultado da empresa. Por fim, na quinta e última seção são tecidas algumas considerações a que este estudo permitiu chegar.

\section{Posicionamento Logístico, Estratégias Operacionais de Produção e Gestão nas Organizações}

\subsection{O Posicionamento Logístico}

Diante da complexidade e alta competitividade existentes no contexto atual, as empresas passam cada vez mais a ter que buscar estratégias que lhe permitem desenvolver diferenciais competitivos em relação às demais empresas, a fim de que aquelas possam se manter no mercado (LAMBERT; STOCK, 1988; WANKE, 2001; HIJJAR et al., 2003; LIMA; PIMENTEL; CARRIERI, 2006). Nesse sentido, a busca pela integração de operações de 
produção e logística constitui-se em importante ponto de estudo, tanto no âmbito interno da empresa, quanto no âmbito externo (da cadeia produtiva de suprimentos), pois permite identificar quais estratégias poderiam ser adotadas por uma dada organização a fim de reduzir custos e, consequentemente, gerar vantagem competitiva em relação às suas concorrentes.

O foco de análise na integração de operações de produção e logística tem possibilitado a identificação de pelo menos três grandes fatores motivadores a partir dos quais as empresas têm tentado atuar visando à redução de custos e a maximização dos benefícios organizacionais: a) a pressão pela redução de estoques, dados os elevados custos de oportunidade de sua manutenção; b) a pressão para agilização do atendimento ao cliente, devido a sua crescente exigência; $e, c)$ a pressão para a customização em massa, isto é, pela criação de variedades nos produtos sem abrir mão de produção em escala (WANKE, 2001).

É justamente nesse sentido que o estudo da estratégia de posicionamento logístico pode possibilitar o alcance de tais objetivos, maximizando os benefícios organizacionais e reduzindo os seus custos (BRONZO; HONÓRIO, 2005). Para Wanke (2001), a estratégia de posicionamento logístico é composta de cinco categorias de decisão organizacionais, que devem ser tomadas de forma coerente e articuladas entre si: 1) a coordenação do fluxo de produtos; 2) a política de produção; 3) a alocação de estoques; 4) a política de transportes; e 5) o dimensionamento da rede.

A primeira delas diz respeito à coordenação do fluxo de produtos $e$ consiste basicamente em saber se a empresa deve ter um fluxo de produtos puxado pelos clientes ou se a empresa deve ter um fluxo de produtos empurrado. No primeiro caso - do fluxo de produtos puxado -, o fluxo é disparado pelo consumidor final ou pelo elo da cadeia mais próximo ao consumidor final. Já no segundo caso, do fluxo empurrado, o fluxo é acionado pelo fornecedor ou pelo elo mais a jusante da cadeia. Para Wanke (2001), essa decisão é a mais importante para uma empresa, pois afetará todas as demais estratégias de produção e distribuição.

Ainda, de acordo com o mesmo autor, a coordenação do fluxo de produto depende de duas grandes variáveis: a) a visibilidade da demanda; e b) o tempo de resposta (ou tempo de ressuprimento e distribuição) por parte da organização. A visibilidade da demanda consiste na capacidade de a empresa obter informações em tempo real sobre a sua demanda efetiva, diferente 
do que ocorre nas práticas tradicionais de previsão da demanda (já que a previsão pode não se concretizar e, muitas vezes, apresenta grande distorção em relação à demanda efetiva). Por sua vez, o tempo de resposta da empresa consiste em saber, a partir da demanda por parte do cliente, em quanto tempo a empresa tem a capacidade de produzir um determinado produto para reabastecer seu cliente. Considerando essas duas variáveis, a empresa pode se caracterizar dentro de um continuum: de um lado estaria a coordenação de fluxos empurrados, que se caracteriza por um longo tempo de resposta e pela ausência de visibilidade da demanda; ao centro estariam os sistemas híbridos, em que há alguma, mas pouca, visibilidade da demanda ou um curto prazo de resposta; e do outro lado, a coordenação de fluxos puxados, na qual haveria uma ampla visibilidade da demanda e um rápido tempo de resposta.

Uma segunda categoria de decisão a ser tomada pela organização é a política de produção, que pode ser feita de duas formas: por estoque ou contrapedido. A produção por estoque consiste em comprar e transformar insumos acabados no presente momento e em antecipação à demanda futura, já que muitas vezes não se tem uma boa visibilidade da demanda. Já a produção contrapedido baseia-se na postergação máxima, em termos de tempo, da compra e transformação de insumos em produtos acabados (WANKE, 2001).

Uma terceira categoria de análise é a alocação de estoques, que pode ser centralizada em um único lugar ou descentralizada em vários locais, centros de distribuição regionais ou por tipo de produto. Essa estratégia de alocação de estoques está intimamente relacionada às duas anteriores, mas também às características do produto e da demanda. Assim, a centralização de estoques significa uma tentativa de postergação ao máximo do transportes de produtos, só movimentando-os a fim de atender o cliente final. Por outro lado, a descentralização dos estoques representa uma maior movimentação entre instalações intermediárias, com base em previsões de vendas, sendo, portanto, mais associada à coordenação de fluxo empurrada e à política de produção por estoques (WANKE, 2001).

A quarta categoria de decisão da organização refere-se à política de transportes, que consiste em analisar se a empresa deve operar com um único meio de transporte ou com transportes intermodais, e também se a empresa deve utilizar meios de transporte rápidos para garantir um serviço premium, ou se a empresa pode utilizar um tipo de transporte convencional.

Por fim, a quinta decisão consiste no dimensionamento da rede que a empresa deve ter, ou seja, quantas instalações, qual a sua localização e que 
Thiago Duarte Pimentel • Alexandre de Pádua Carrieri • Alfredo Rodrigues Leite da Silva

produtos devem ser alocados em cada uma delas (WANKE, 2001). Essas decisões seguem as mesmas características de restrição das outras quatro decisões relacionadas acima.

Hijjar et al. (2003), ao analisar a evolução do desempenho logístico das indústrias de bens de consumo a partir da ótica do setor varejista, afirma que no contexto atual a adequação do serviço logístico pode ser fator essencial de ganho de competitividade. Para Hijjar et al. (2003) a adequação do posicionamento logístico às expectativas do cliente consiste em saber ofertar aquilo que lhe é demandado, nos prazos certos e nos locais mais propícios. Assim, o entendimento das categorias de posicionamento logístico estipuladas por Wanke (2001) assume um papel de suma importância, pois contribuem diretamente para o entendimento dessa dinâmica de adequação do posicionamento logístico em relação à demanda que lhe é estabelecida.

Fleury e Lavalle (1997) avaliando o serviço de distribuição física, com base na relação entre indústria de bens de consumo e o comércio atacadista e varejista, apesar de se concentrar no aspecto da distribuição, já ressaltam a importância que esse processo tem em relação aos custos e ao posicionamento logísticos. Uma importante contribuição do trabalho de Fleury e Lavalle (1997) consiste em ressaltar o processo de estreita ligação entre as dimensões avaliadas nas decisões do posicionamento logístico de um produto e no resultado gerado a partir de tais decisões, ou seja, de que forma essas decisões são percebidas pelos clientes.

Com base nesses argumentos é que o presente estudo se propõe - em conjunto com o gestor familiar - a identificar, descrever e analisar as decisões de posicionamento logístico adotadas em uma organização familiar, enfatizando a dimensão das estratégias de produção e gestão de operações.

\subsection{Estratégias de Produção e Gestão de Operações}

Autores como Skinner (1969) comentam sobre o papel estratégico que a manufatura deve ter na competitividade da organização como um todo, desde os mais altos aos mais baixos escalóes. Alguns dos papéis que a manufatura e a organização assumem na busca da excelência podem ser sumarizados da seguinte forma:

a) A manufatura é dada como arma competitiva poderosa, pois alguns dos critérios que são exigidos pelos clientes, como produtos 
sem defeitos, confiáveis, entregas confiáveis e rápidas, dependem dessa área;

b) A manufatura deve contribuir com eficácia e não só com eficiência em custos. Portanto, deve criar novos critérios de avaliação de desempenho voltados para dimensões como qualidade, confiabilidade, prazos e flexibilidade;

c) Há uma significativa necessidade de determinação do foco. De modo similar ao que Porter (1990) ressaltou acerca da escolha da estratégia para se alcançar a vantagem competitiva, a manufatura não pode, simultaneamente, atuar com vários critérios. Ela, juntamente com os outros setores da organização, precisa descobrir e priorizar o que é mais importante para seu cliente, seja interna ou externamente;

d) Hoje em dia, há uma necessidade por parte da manufatura de utilizar intensamente as ferramentas de comunicação, a fim de aprimorar e flexibilizar a filosofia burocrática de organização - com estruturas tradicionais e hierarquizadas - que tem predominado na manufatura. Como já foi mencionado por Simon (1965), a comunicação organizacional é um fator crucial para a tomada de decisões de modo mais eficaz, pois, devido à racionalidade limitada dos decisores, o compartilhamento de informações pode trazer novas variáveis para a avaliação dos cenários e, consequentemente, possibilitar uma tomada de decisão mais acertada. Assim, há que se integrar os diversos setores organizacionais para que as diretrizes estejam bem claras, compartilhadas e coordenadas, inclusive em níveis superiores, para o sustento das decisões;

e) Manufatura também deve ser pró-ativa, e não apenas reativa. Ela não pode apenas assumir um papel reativo no contexto em que está inserida, mas sim agir de forma pró-ativa antecipando as tendências do mercado (como novas tecnologias e metodologias). Nesse ponto, vale ressaltar as contribuições de Chandler (1976) em relação à estratégia organizacional;

f) Por fim, as estratégias devem ser consideradas como um padrão de decisões, não apenas como um documento de intenções. Nesse 
Thiago Duarte Pimentel • Alexandre de Pádua Carrieri - Alfredo Rodrigues Leite da Silva

aspecto é importante que cada tomador de decisão tenha em mente as mesmas diretrizes, e ressalta-se novamente o papel do sistema de informação (comunicação) para apoiar a decisão. Buscam-se decisões coerentes, que possam convergir mais facilmente para a competitividade (SKINNER, 1969).

Correa e Gianesi (1996) estipula um padrão de decisões para as principais áreas de decisão. Segundo esse autor, há que se considerar os seguintes critérios: 1) a capacidade de produção, ou seja, o nível, tipo, como e com que rapidez incrementar; 2) as instalações, representadas pelo arranjo físico, tamanho, localização, especialização, políticas de manutenção; 3) a tecnologia, quais equipamentos, o grau de automação, flexibilidade e versatilidade; 4) a integração vertical, que mostra em que direção e com qual extensão deve ter a manufatura; 5) a força de trabalho, que mostra os níveis de especialização, as políticas salariais e planos de carreira; 6) a qualidade, ou seja, os mecanismos de prevenção de falhas, a monitoração, o nível de intervenção, quais são os padrões, e os mecanismos de benchmarking adotados; 7) o fluxo de materiais, as políticas quanto aos fornecedores, os sistemas de administração da produção, qual o papel dos estoques, o sistema de distribuição; 8) o desenvolvimento de novos produtos, que tem como foco garantir a frequência e a rapidez necessárias na introdução de novos produtos; 9) as medidas de desempenho, quais critérios têm prioridades, que medidas os representam, os padrões adotados, os métodos utilizados, e a frequência de controle e, por fim; 10) a organização, vista pelo nível de centralização, estilo de liderança, o fluxo de comunicação nos níveis necessários, e o processo de tomada de decisão.

Já para autores como Correa e Gianesi (1996), existem cinco prioridades competitivas às quais a manufatura pode contribuir para a competitividade da organização: gastar menos na produção do que os concorrentes; produzir produtos melhores do que os concorrentes; fazer mais rápido; atender no prazo prometido a demanda; e ser capaz de mudar rápido para obter uma flexibilidade maior do que o concorrente. Vale ressaltar a importância da divisão dessas prioridades em ganhadores de pedidos e critérios qualificadores.

Um sistema de materiais deve estabelecer uma integração desde a previsão de vendas, passando pelo planejamento de programa-mestre de produção até a produção e a entrega do produto final. Precisa controlar a cadeia, consumidor, varejista, atacadista e fabricante, tendo como principal 
abordagem a velocidade de informação e o controle rígido na reposição dos estoques (DIAS, 2005). Como foi citado por Lambert e Stock (1988), a administração de materiais caracteriza-se por quatro atividades básicas: 1) Antecipação de necessidades de materiais; 2) Identificação da fonte e obtenção de materiais; 3) Introdução de materiais na organização; e 4) Controle da condição dos materiais como um ativo corrente. Lambert e Stock (1988) ressaltam também os aspectos essenciais como compras e suprimentos; controle da produção; tráfego e transporte do recebimento; armazenagem e estocagem; planejamento e controle do estoque; e descarte de resíduos e refugos.

Assim, a questão chave que se coloca na definição de estratégias de produção e gestão de operações é descobrir uma vantagem competitiva sabendo explorar os pontos fortes e se precaver dos pontos fracos, dentro do contexto e cenário de cada organização, ou seja, analisar aquelas dimensões consoantes à especificidade de cada organização como, por exemplo, no caso das micro-organizações familiares, em que o próprio tamanho e a estrutura contribuem para diferenciar e fazer ressaltar alguns critérios de adaptação. Portanto, não existe uma "receita de bolo", mas sim uma tarefa de adaptação ao contexto que pode ter (ou gerar) situações e possibilidades diferentes para que uma dada empresa possa alcançar a competitividade.

\section{Caminhos Percorridos}

Este trabalho desenvolveu-se sob a forma de uma pesquisa qualitativa (TRIVINÕS, 1987), que pode ser entendida como "[...] um conjunto de práticas interpretativas, mas [que] não privilegia qualquer tipo de metodologia, inexistindo teoria ou paradigma que lhe seja próprio", e que se caracteriza pela utilização de vários tipos de métodos científicos, como, por exemplo, a análise do discurso e a análise de conteúdo; e também empíricos, como o estudo de caso, a pesquisa-ação e análise de documentos históricos (LUZ, 2001, p. 95).

Como método de análise empírica utiliza-se o estudo de caso que consiste na investigação aprofundada de um objeto devido à sua relevância (TRIVIÑOS, 1987) face ao contexto estudado. Para Yin (2001), o estudo de caso consiste numa investigação empírica de um fenômeno social cujos limites com o seu contexto não são bem definidos, exigindo, portanto, a utilização de várias fontes para adentrar na sua essência. Ainda, segundo o autor, 
esse tipo de estudo é útil para pesquisas de caráter exploratório, mas também para estudos descritivos e explanatórios, como é o caso deste trabalho.

De modo complementar, utilizou-se a pesquisa-ação como método de pesquisa. Embora seja recente nos estudos organizacionais (EDEN; HUXHAM, 2001), a pesquisa-ação insere-se como uma estratégia de conhecimento que foca essencialmente o processo ocorrido entre conhecimento e ação (THIOLLENT, 1988). Esse processo se dá em dois níveis: no campo do agir (ação social, política, jurídica, moral) e no campo do fazer (ação técnica). Assim, a passagem do conhecer ao agir supõe transformação: "a situação está assim [...] temos que fazer isso ou aquilo para alterar tal situação" (THIOLLENT, 1988, p. 40).

Nesse sentido, uma das reais contribuições da pesquisa-ação é a geração de novos conhecimentos, por meio da pesquisa, e a aplicação desses conhecimentos no contexto em que ele é gerado (como, por exemplo, o organizacional) a fim de estimular a solução de problemas. Esse tipo de pesquisa pode contribuir para o desenvolvimento organizacional por meio de processos de aprendizagem.

No presente estudo utiliza-se a pesquisa-ação de caráter instrumental, cujo foco pauta-se na resolução de problemas técnicos como, por exemplo, a solução de problemas dentro de uma organização. Objetiva-se, juntamente com os gestores da organização familiar, identificar, descrever e analisar o posicionamento logístico e as estratégias de produção e gestão de operações da empresa. Por sua vez, ela pode apontar possíveis soluções para o problema de posicionamento logístico de seus produtos.

Como procedimento para a coleta de dados adotou-se a entrevista em profundidade que segundo Triviños (1987, p. 146) é

[...] aquela que parte de certos questionamentos básicos, apoiados em teorias e hipóteses, que interessam à pesquisa, e que, em seguida, oferecem amplo campo de interrogativas, fruto de novas hipóteses que vão surgindo à medida que se recebem as respostas do informante [...].

Sua principal característica é a possibilidade do informante se abrir (falar) na entrevista e, portanto, revelar informações importantes para a pesquisa. Para isso, desenvolveu-se um roteiro semi-estruturado para entrevistas em profundidade, como ferramenta de apoio, de forma a propiciar maior 
liberdade e flexibilidade no tratamento das questões, na medida em que essas se mostraram relevantes para o estudo.

Foram realizadas várias sessões de entrevista em diferentes locais (na manufatura, no show room, na feira, e em sua casa) e contextos com a mesma pessoa, o proprietário-gestor da organização familiar em questão. Eventualmente, algumas informações especificas - comerciais e técnicas, respectivamente - foram complementadas por sua filha, que o ajuda na parte administrativa do empreendimento, e por aprendizes e funcionários que atuam na linha de produção.

Já em relação ao tratamento dos dados utilizou-se a técnica da Análise de Conteúdo (BARDIN, 1988), que pode ser considerada como uma técnica de tratamento e análise da comunicação, composta por procedimentos sistemáticos e objetivos de descrição do conteúdo das mensagens, indicadores e dados em geral, que permitem identificar o que está sendo dito sobre determinado tema (VERGARA, 2005). Esse passo foi realizado em três etapas distintas, porém complementares, como assinala Triviños (1987): a) pré-análise; b) a descrição analítica; e c) a interpretação do material analisado.

A pré-análise consiste nos processos de classificação, ordenação e leitura flutuante de todo o material coletado, com vistas a obter um panorama geral do estudo e delimitar possíveis recortes e hipóteses de estudo. Já a fase de descrição analítica começa com a delimitação do recorte a ser estudado ainda na pré-análise, e tem como objetivo focar o corpus que deverá ser estudado de modo aprofundado. Nessa fase, aplicam-se os procedimentos de codificação, classificação e categorização do material coletado, por critérios de afinidade, como o perfil ou a atuação profissional, entre outros. Por fim, a fase de interpretação corresponde à análise do material baseado na reflexão e intuição, relacionando o conteúdo manifesto (explícito) do texto com o conteúdo latente (implícito) para descobrir os modos de pensar, as tendências, ou fenômenos sociais expressos no material coletado (TRIVIÑOS, 1987).

Assim, considerando a análise temática de conteúdo e as principais características do conceito de posicionamento logístico propostas por Wanke (2001), as categorias analisadas neste estudo foram: a) a coordenação do fluxo de produção, com os subtemas da visibilidade, da demanda, e tempo de resposta; b) a política de produção da organização; c) estratégias de produção; d) alocação de estoques; e) política de transporte; e f) dimensionamento da rede de produção. Para fins específicos de análise, recorreu-se neste estudo à utilização de trechos específicos da entrevista realizada, meramente como 
Thiago Duarte Pimentel • Alexandre de Pádua Carrieri • Alfredo Rodrigues Leite da Silva

forma de ilustração da análise por nós realizada. Tais trechos encontram-se numerados em ordem crescente ao longo da análise.

\section{Análise de Posicionamento Logístico e das Estratégias de Produção e Gestão de Operações $K^{4}$ Manufatura Têxtil}

\subsection{Caracterizando a Empresa K Manufatura têxtil}

A empresa K é uma organização familiar que surgiu em 1978 atuando no setor têxtil da Feira de Arte e Artesanato de Belo Horizonte, conhecida popularmente como Feira Hippie. Naquela época a organização era constituída basicamente pelos membros da família, sob a orientação e supervisão do pai, que no caso exercia o papel de gestor e de produtor artesanal. Com o tempo, a organização foi crescendo e incorporando outras pessoas no seu processo produtivo. Essas pessoas eram tidas como aprendizes de artesão $e$ exerciam uma função semelhante à de qualquer outro empregado, embora eles tivessem um maior domínio sobre as diversas etapas produtivas e também uma relação mais participativa junto ao gestor familiar.

Atualmente, a organização $\mathrm{K}$, além de manter a sua atuação dentro da Feira Hippie, possui um show room para a demonstração e negociação de seus produtos fora da Feira. Ela também conta com cerca de 30 a $50^{5}$ pessoas (consideradas como aprendizes de artesão) envolvidas diretamente no processo produtivo de roupas e 300 pessoas envolvidas indiretamente na sua linha de produção. A organização possui um faturamento de cerca de $\mathrm{R} \$$ $180.000,00$ por mês na venda de seus produtos apenas na Feira Hippie. Além disso, a organização K realiza vendas em seu show room, embora esse volume seja bem menor. Ela também exporta parte dos seus produtos para diversos países, como França, Alemanha, Inglaterra e Estados Unidos.

\footnotetext{
${ }^{4} \mathrm{O}$ nome da organização foi substituído pela letra Ka fim de preservar a sua identidade.

${ }^{5}$ Esse número chegou a 50 em virtude de um aumento de produtividade face à demanda do mercado, embora se tenha admitido que o número de aprendizes de artesão que trabalhavam normalmente na linha de produção fosse de 30 pessoas - além do gestor (mestre artesão) e sua familia (mulher e duas filhas).
} 


\subsection{O Posicionamento Logístico da Empresa K}

\subsection{A Coordenação do Fluxo de Produção}

A análise do fluxo de produção da empresa $\mathrm{K}$ pode ser considerada como um tipo de sistema híbrido, como coloca Wanke (2001), devido ao fato de que há pouca visibilidade da demanda, porém há um tempo de resposta muito rápido em relação ao caráter de seus produtos - manufatura artesanal têxtil de produção em média escala. Os produtos seguem uma linha artesanal em sua concepção, no sentido de serem produzidos manualmente e em termos de sua exclusividade. Em seguida, cada peça é reproduzida em escala, tentando-se manter certo grau de diferenciação entre cada uma delas, mas dentro do mesmo processo produtivo e utilizando as mesmas máquinas e os mesmos tipos (design) de bordados.

De acordo com o entrevistado, conforme o trecho (1), há necessidade de se ter grande número de funcionários indiretos porque "[...] eu expandi esse lado do bordado e eu já venho trabalhando com o bordado só de uns 3 a 4 anos para cá [...] e uma camiseta minha para bordar ela gasta 2 dias e meio para bordar cada peça" (trecho 1).

Como a produção de peças bordadas é manual e gasta um tempo maior do que aquela feita em maquinário, para que se consiga ter grande produção é preciso ter também alto número de funcionários, porém esses funcionários são considerados como indiretos, pois não trabalham dentro da organização estudada, mas sim como terceirizados, seja individualmente ou como empresas, prestando serviços para a organização K.

É interessante ressaltar que a empresa possui um fluxo híbrido porque se, de um lado, existe um tempo de resposta relativamente rápido para se bordar cada peça, a organização, por outro, ainda não desenvolveu um sistema de analisar a demanda real de mercado. Nesse sentido, a produção é, essencialmente, realizada de modo empurrado, pois sempre é necessário ter algum estoque ou peças em produção para que se possa atender a possível demanda esperada. Contudo, o sistema de produção da empresa K não possui um fluxo de coordenação totalmente empurrado já que o tempo de resposta de produção é relativamente rápido e isso faz com que o gestor consiga postergar a produção em virtude da confirmação ou não de uma demanda real. 
Thiago Duarte Pimentel • Alexandre de Pádua Carrieri • Alfredo Rodrigues Leite da Silva

Outro fator que contribui para que a coordenação do fluxo de produção seja híbrida é o fato de a organização estudada ter desenvolvido um conjunto de estratégias, como, por exemplo, a venda antecipada ou por encomenda, a fim de flexibilizar o sistema produtivo fornecendo à organização uma possibilidade de se adaptar às exigências do ambiente competitivo.

\subsubsection{A Política de Produção}

A política de produção da empresa é baseada na criação de estoques, visando antecipar-se a uma possível demanda de clientes sobre a quantidade de produtos. A quantidade de peças estimadas para a produção é feita semanalmente, já que a Feira Hippie ocorre todos os domingos e a produção visa atender a demanda da Feira. De acordo com o entrevistado, quem decide a quantidade de produtos que será feita durante cada semana é o próprio gestor. Ele faz isso com base em dois tipos de informação: a) a demanda de pedidos de clientes já consolidados, clientes fiéis que sempre compram uma determinada quantidade de produto toda semana; $e$ b) com base na estimativa de venda das semanas anteriores, ou seja, utilizando-se de séries temporais de análise da evolução da produção. Vale ressaltar que essa estimativa da evolução das semanas anteriores é realizada de modo informal, ou seja, não existe nenhum procedimento de operação padrão para fazê-lo. Nesse ponto o gestor reconhece a necessidade de melhorar as práticas de gestão e de controle, conforme expresso no trecho (2), (2) [...] eu agora estou até tentando me profissionalizar nessa área. Mas sempre foi pelo chutometro mesmo. Acompanhando as vendas das semanas anteriores. Sempre foi assim [...] Hoje não. Hoje eu estou me profissionalizando. Eu tenho secretária, tenho computador. Já tenho todo um esquema. Tenho pessoas para me ajudar. Mas sempre fui autodidata mesmo. Eu sendo artesão. [...] sempre fazia tudo. Agora não. Agora não, estou tentando delegar [...] agora eu estou aprendendo a delegar poderes.

Porém, apesar de se ter uma produção voltada para a fabricação de estoques visando a atender uma futura demanda, há que se ressaltar que o tempo de ciclo da produção - semanal - é um fator que contribui para a minimização de custos com estoques, já que a produção que não é vendida fica encalhada de uma semana para outra. Mas o fator mais importante a ser considerado é o fato de que a organização $\mathrm{K}$ concentra o processo produtivo de criação das peças consigo. Essas peças são consideradas moldes para 
a produção em escala que será executada pelos trabalhadores terceirizados, ou seja, aqueles que não fazem parte da empresa e que, portanto, não incorrem em custos para ela.

Esses trabalhadores terceirizados são responsáveis por grande parte da produção e também concentram os estoques em suas mãos, pois a organização K repassa a quantidade de peças demandadas para os chefes de cada equipe (aqui pode ser feito uma analogia com o conceito células) que, por sua vez, repassam os pedidos para os bordadeiros, que vão confeccionar as peças ao longo da semana. Cada equipe funciona como se fosse uma miniorganização ou miniempresa (só que informal). Essas equipes arcam com seus próprios custos de estoques, já que elas produzem com o seu próprio material, desonerando assim a empresa $\mathrm{K}$ dos custos com estoque ou com peças defeituosas porque, conforme os trechos (3) e (4), (3) [...] tem peças que eu forneço o material porque a pessoa é muito pobre e não tem condições de comprar. E tem equipes que não, que já me fornecem com o produto deles. (4) [...] Cada um já controla a sua equipe e já me dá o trabaIho revisado. Eu só tenho contato com os chefes das equipes.

Esse processo produtivo revela as estratégias adotadas pela organização $\mathrm{K}$, que possui uma estrutura enxuta em termos dos trabalhadores diretos da empresa, pois só concentra em si aqueles que trabalham efetivamente na criação das peças e na montagem de moldes que posteriormente serão repassados aos chefes de equipes, que por sua vez repassarão aos bordadeiros (funcionários indiretos ou terceirizados) para confeccionarem as peças de acordo com o modelo. Assim, a política de produção da organização K é extremamente flexível, pois de acordo com o seu processo, no centro da organização há uma célula produtiva que cuida da criação das peças que serão produzidas. No âmbito externo da organização existem alguns fornecedores de mão de obra que trabalham por conta própria e que assumem a responsabilidade de produzir as peças demandas pela organização $\mathrm{K}$, em quantidades e qualidades desejadas, assumindo também a responsabilidade pelos estoques e pelos refugos de mercadoria.

\subsubsection{Estratégias de Produção}

As estratégias de produção da organização $\mathrm{K}$ podem ser enquadradas em duas categorias distintas: as estratégias produtivas e as estratégias de gestão de operações da empresa. As estratégias produtivas correspondem àque- 
las que são empregadas no processo produtivo da organização em relação aos seus principais produtos, como, por exemplo, a criação de modelos $e$ coleções de peças a serem reproduzidas pelos fornecedores ou funcionários indiretos da organização (as equipes de trabalho). Já as estratégias de gestão de operações correspondem à forma como a organização $\mathrm{K}$ gere a rede de relações que ela estabelece com as equipes de trabalho que desenvolvem a parte de confecção das peças bordadas.

As estratégias de produção da organização $\mathrm{K}$ refletem como o processo de produção está inserido em um continuum entre a produção totalmente artesanal, feita em pequena escala e com total exclusividade, e a produção manufaturada, repetida em série a fim de se atingir uma escala que viabilize a comercialização das roupas, sejam elas bordadas ou não. Para ilustrar, o trecho (5) destacado abaixo revela a viabilidade e complementaridade das estratégias adotada pela organização. (5) Sempre trabalhei dentro da linha artesanal, mas o meu negócio que é você pegar a matéria-prima bruta e transformar em bem utilitário. Transformar a matéria-prima bruta (que seria o fio de algodão ou o fio da viscose) em roupa (material utilitário). Só que eu tenho técnicas de trabalho em cima da matéria prima bruta. Então, atualmente, trabalho na Feira, eu estou trabalhando com serigrafia. Aerografia. E bordado que é uma técnica bem diferente porque ela agrega vários produtos. [...] Era uma caneta vaporizadora ligada a um compressor que sai um jato de tinta. E aí você vai acompanhando o desenho e fazendo o desenho todo à mão. E então é um trabalho todo exclusivo que depois é todo fotografado e fabricado em série. Aerografia hoje é fotografada e depois vai para o computador e é feita em série.

Com relação às estratégias de operação, a organização $\mathrm{K}$ trabalha com a gestão de equipes de produção, como se fossem células produtivas, porém externas à empresa. Esse processo assemelha-se, como descrito pelo próprio entrevistado, a um processo de terceirização, já que as equipes de trabalho funcionam como fornecedores de produtos acabados para a organização K. Assim, essa organização adota como estratégia de gestão dessas operações realizadas de forma terceirizada, o seguinte processo: (6) [...] a primeira peça sou sempre eu que faço. E aí eu procuro uma pessoa e treino essa pessoa para ela ser o aprendiz do artesão e ela vira uma chefe de equipe. E aí ela começa a trabalhar em cima da peça piloto. E essa pessoa que eu formei como aprendiz de artesão. [...] E então ela vai fazer o produto por ela mesmo. E então do ateliê ela vai pegar o produto estampado e tingido e ela 
vai só bordar. E ela vai formando as equipes. E as equipes só vão crescendo cada vez mais dependendo da minha demanda. [...] E a partir da hora que a pessoa vai aprendendo ela vai montando a equipe para ela. E isso também vai ajudar ela a ganhar mais dinheiro. Porque ela pega o bordado na minha mão há 10 reais, e ela pode pagar o aprendiz de bordado dela 7 reais, vamos supor, e ganhar 3 reais. E até ele ficar fera. E na hora que ele ficou bom no trabalho, ele monta a equipe dele e passa a pegar os meus 10 reais. É uma terceirização.

Assim, o processo de gestão das operações por parte da organização K é feito com base no relacionamento entre ela e as demais organizações informais, denominadas de equipes de trabalho, que fazem toda a parte de produção das peças a serem vendidas pela organização K. Vale ressaltar que o controle das atividades realizadas pelas equipes é feito pelo chefe de cada uma delas. Esse chefe por sua vez se reúne com o gestor da organização $\mathrm{K} \mathrm{a}$ fim de prestar contas e esclarecimentos sobre o andamento da produção, a qualidade dos produtos e as formas de pagamento. $\mathrm{O}$ pagamento, por exemplo, é feito por peça, já que "[...] a peça é terceirizada e então a bordadeira é free lancer e então ela recebe por peça. É tudo pago por peça. E de acordo com o bordado" (trecho 7).

\subsubsection{Alocação de Estoques}

A política de alocação de estoques, como foi dito anteriormente, assim como a parte de produção das peças, é terceirizada. Ou seja, a responsabilidade pelos custos adquiridos com os estoques e, eventualmente, pelo refugo de peças por parte da organização K, é assumida integralmente pelas equipes de trabalho. Nesse sentido, a organização K arca apenas, e parcialmente, com o risco de não se ter uma peça produzida para ser entregue ao cliente, caso haja alguma falha na produção ou as equipes de trabalho não entreguem as peças com a qualidade desejada, no prazo esperado pela organização K.

(8) E no final essas pessoas [bordadeiros de cada equipe] passam esses bordados para o chefe da equipe que, por sua vez, repassam os bordados para mim [organização $K$ ]. E em cada peça se tiver algum defeito ela volta para a pessoa que a fez. E se tiver tudo ok ela vai direto para a venda. Passa para o chefe de equipe, porque é ele quem confere e repassa para a organização $K$, que a reconfere e se tiver tudo ok. E ela não tem prejuízo nenhum. 
Esse é um problema enfrentado pela organização $\mathrm{K}$, que se restringe à questão contratual, ainda que não haja um contrato formal entre as partes a organização $\mathrm{K}$ e as equipes de bordadeiros (PERROW, 1972). Contudo, a organização $\mathrm{K}$ parece lidar bem com essa questão, já que há um crescimento do número de grupos de bordadeiros terceirizados pela organização $\mathrm{K}$ que, recentemente, passou de um contingente de 200 para um contingente de 300 pessoas envolvidas nas equipes de produção das peças.

Outra questão relevante é o fato de que, por um lado, a organização $\mathrm{K}$ praticamente não tem custos com a alocação de estoques (já que esses são de responsabilidade das suas equipes de fornecedores). Mas, por outro lado, ela tem que arcar com um duplo processo de conferência da qualidade dos produtos, pois são conferidos ao saírem das células de fornecedores e reconferidos pela organização $\mathrm{K}$, quando esta os recebe. Isso, por sua vez, resulta em retrabalhos e, consequentemente, em custos para a organização K.

\subsubsection{A Política de Transporte}

A política de transporte da organização $\mathrm{K}$ também é, basicamente, dependente das equipes de produção, pois essas equipes além de realizarem toda a parte produtiva das peças (desde camisas simples até as bordadas, utilizando os próprios insumos), ainda repassam essa produção para os chefes de equipe que conferem a qualidade e fazem os pagamentos aos bordadeiros. Em seguida, os chefes de cada equipe é que transportam as peças produzidas e coletadas junto às suas equipes até o show room da organização K. Dessa forma, a organização K não arca nem com os custos de transporte para o recolhimento das peças junto aos chefes de cada equipe.

No trecho (9) aparece a explicação para esse processo, que seria devido ao pagamento por peça e à produtividade individual de cada bordadeiro, que prefere ficar em casa a trabalhar em um emprego formal, pois em casa ele consegue um retorno financeiro muito maior do que em um emprego formal, além de não gastar com transporte nem com alimentação por não ter que se deslocar de casa. Por isso, essas equipes de produção estariam incorporando os custos de transporte semanal da produção até a organização $\mathrm{K}$, pois ainda assim esses custos seriam inferiores aos de seu deslocamento diário até organização - como ocorre em empregos formais. 
(9) Porque para eles [os homens chefes de família] é mais vantajoso ficar em casa bordando e deixar de gastar dinheiro com ônibus, com comida e alimentação e perder tempo indo e voltando do trabalho o que seria mais cansativo. Eles estão preferindo ficar em casa bordando junto com a esposa e filhos, bordando e ganhando o seu dinheiro livre e em casa. E o que depende da produção, [...] [segundo o gestor familiar] cada peça varia entre 10 e 15 reais dependendo do modelo e do grau de dificuldade da blusa. Mas o valor é o mesmo por peça pago a cada pessoa. Então tem pessoas que fazem dois bordados por semana e tem pessoas que fazem 10.

\subsubsection{O Dimensionamento da Rede de Produção}

Atualmente a rede de produção da organização K está se ampliando consideravelmente. Há várias equipes de trabalho que atuam sob a sua coordenação, e ainda existe a perspectiva de aumento dessas equipes devido à crescente demanda dos produtos da organização K. Isso leva uma tendência de crescimento das equipes. O tamanho da rede ainda está centrado em duas equipes, mas há um constante crescimento dessas equipes, conforme destacado no trecho (10).

(10) Porque a minha equipe de bordadeiras como [...] eu trabalho com o trabalho muito artesanal ele requer muitas pessoas trabalhando. Hoje para eu vender 100 peças, por exemplo, eu tenho que ter no mínimo 200 bordadeiras. [...] Porque o trabalho é muito elaborado. Então, eu trabalho com as [pessoas das] cidades fora, principalmente Pedro Leopoldo, Sete Lagoas, São José da Lapa. Toda região da grande BH [Belo Horizonte/MG]. E pretendo agora expandir para Esmeraldas. Que é a terra do bordado.

(11) Têm várias equipes e que uma só equipe é coordenada por uma chefe de aprendiz e tem 280 bordadeiras que trabalham para ela diretamente. Ele coordena e lidera estas 280 bordadeiras. [...] E esta é só uma das equipes. Além disto, tem várias outras equipes [...] que está se destacando.

Essa questão do dimensionamento foi identificada como principal gargalo a ser enfrentado pela organização K, já que essa organização possui uma estrutura reduzida e, além disso, a especificidade do produto artesanal manufaturado em média escala faz com que a organização K tenha dificuldades em desenvolver uma rede de produção muito extensa, pois os elos não são muitos firmes ou fixos. Nesse sentido, torna-se difícil confiar que a produção esperada das células (equipes de trabalho) seja realmente cumprida, 
Thiago Duarte Pimentel • Alexandre de Pádua Carrieri • Alfredo Rodrigues Leite da Silva

já que ela pode variar muito de uma semana para a outra. Essa variação ocorre, principalmente, por dois motivos: a falta de compromissos formais (contratos formais) estabelecidos entre a organização $\mathrm{K} e$ as equipes de bordadeiros; e o próprio estímulo e motivação de produção de cada equipe. Um forte problema enfrentado é a capacitação dos chefes de equipe. Devido à necessidade de grande quantidade de mão de obra é necessário também que haja a formação de grande contingente de chefes de equipe para poder gerenciar cada uma delas.

Outro forte motivo, que dificulta a expansão da organização $\mathrm{K}$, é a falta de capital. A dificuldade de conseguir financiamento para a expansão de suas atividades parece ser um problema comum entre as pequenas empresas, pois

(12) burocracia é muito grande para o artesão. Eu já cheguei uma fase de artesão para pequeno empreendedor. Pequeno empresário porque o produto ainda continua sendo artesanato. Então é muito complicado você ser empresário com um produto artesanal. Então você está sendo um pequeno empreendedor. A demanda como é muito grande eu preciso de mão de obra. Muita mão de obra.

Apesar disso, o próprio gestor familiar considera que "[...] o futuro de qualquer artesão é realmente virar indústria, ter mais produto para atender a demanda" (trecho 13).

Assim, apesar de apresentar grande potencial de crescimento, o dimensionamento da rede de produção - até mesmo em virtude da ampliação das cidades em que ficam as equipes de bordadeiros - apresenta um fator crítico de sucesso para a organização K, sendo o principal desafio a ser enfrentado.

\section{Considerações Finais}

O presente artigo teve por objetivo identificar, descrever e analisar, junto com o gestor da organização, a estratégia de posicionamento logístico, enfatizando as decisões relativas às estratégias de produção e operações, baseando-se para isso em estudo de caso de uma pequena organização familiar.

Os resultados apontados evidenciaram a adoção de estratégias diferenciadas e bastante flexíveis, no sentido de que a organização tem lançado 
mão de diferentes técnicas de produção e gestão de operações para atingir seus objetivos organizacionais. Exemplos de tais estratégias foram evidenciados tanto na diferenciação da produção em relação aos concorrentes, em termos de produto, quanto na diferenciação com base em estratégias de gestão de suas operações produtivas e de gestão das equipes de produção terceirizadas.

O desenvolvimento dessas equipes de trabalhadores terceirizados pode ser considerado como a principal estratégia de gestão da organização $\mathrm{K}$, já que, dentre outros fatores, essa estratégia contribui para tornar a coordenação dos fluxos de produção dentro de uma forma flexível. Ela também contribui para minimizar os efeitos de custo de estoque, mesmo tendo uma política de produção voltada para estoques semanais. $\mathrm{O}$ fato dos estoques serem semanais também é um ponto positivo, pois diminui a possibilidade de se ter custos elevados por longos períodos de tempo. Ainda sobre os estoques é possível afirmar que a organização K acaba por transferir grande parte de seus custos para as equipes que trabalham de forma terceirizada. É assim que a organização K obtém boa parte de sua vantagem competitiva.

Quanto às questões do transporte é possível afirmar também que as equipes de produção terceirizadas é que arcam com grande parte dos custos de produção da organização. Isso é conseguido porque esse processo de terceirização leva a uma degradação do trabalho, já que as equipes não recebem encargos sociais ou trabalhistas, atuando apenas como autônomos. Outro ponto que merece atenção é o dimensionamento da rede de produção, que foi o ponto identificado como o maior gargalo da organização $\mathrm{K}$, juntamente com a questão da conquista de financiamentos para investir no aumento da produção.

Dessa forma, foi possível observar como resultado que, assim como as grandes organizações, as pequenas empresas familiares também adotam estratégias de posicionamento logístico de seus produtos e de gestão da produção e operações, embora tais estratégias possam ser caracterizadas como tácitas ou emergentes, por muitas vezes não seguirem um planejamento formal deliberado pelo gestor. Mesmo assim, pode-se inferir que pequenas empresas familiares apresentam características de utilização de conceitos e categorias de logística e de estratégias de produção e de gestão de suas operações como uma forma de se manter competitiva e atuante no turbulento e exigente mercado competitivo atual. 
Thiago Duarte Pimentel • Alexandre de Pádua Carrieri • Alfredo Rodrigues Leite da Silva

Nesse sentido, uma das contribuições desse trabalho consistiu em fornecer subsídios à solução de problemas de gestão encontrados na organização pesquisada, como, a identificação do gargalo na gestão das redes de bordadeiros que, a priori, mostrava-se como o grande diferencial competitivo desse empreendimento familiar, mas que, de fato, estava sendo subadministrado devido à escassez de procedimentos formais de planejamento e gestão. Assim, buscou-se, ainda que parcialmente, formas de contribuir para que o gestor daquela organização familiar pudesse selecionar, da melhor forma possível, mecanismos para interferir na realidade de sua organização objetivando o aumento da eficiência $e$ a maximização dos seus benefícios.

Um dos mecanismos propostos foi a formação de uma cooperativa de bordadeiros (em virtude de seu grande número) para gerir e negociar produtos, estoques e o próprio trabalho de mão de obra terceirizada para a organização $\mathrm{K}$, de forma mais eficiente e segura. Se por um lado tal mecanismo leva a formação de contratos formais, mais estáveis e seguros, protegendo inclusive àquela organização de eventuais perdas por falta de produção ou produtos fora das especificações exigidas; de outro, eventualmente pode incorrer no aumento de custos para a organização K. De qualquer forma, acredita-se que apesar dos custos tal medida seria benéfica para cadeia como um todo, pois traria consigo certa formalização da cadeia e sua integração ao sistema produtivo formal-legal que, em última instância, confere vantagens de proteção social aos trabalhadores, assim como mais credibilidade e transparência aos produtos da organização $\mathrm{K}$, que deixariam de ser vinculados a uma imagem de exploração de mão de obra informal e precária.

\title{
Logistic positionning by prodution's strategies in families micro-organizations: a case study on Textile Sector
}

\begin{abstract}
The strategies of logistic positioning are analyzed, emphasizing that relative to the production and management of operations, in family micron-organizations. One became fullfilled a revision on logistic positioning, strategies of production and
\end{abstract}


operations to base the case of an inserted family organization on the context of the Feira Hippie of Belo Horizonte /MG. The qualitative research was based on the research-action having aimed at to identify, next to the family manager, the strategies of logistic positioning, production and management of adopted operations face to its productive context. It was observed as the family micro-organizations adopt internal strategies (tacit/emergent) and external (development of social nets), that they guarantee economic viability even so to them transfer costs to the suppliers.

Key-words: Logistic positioning. Strategies of production and operation. Research-action. Family organizations.

\section{REFERÊNCIAS}

ANPAD 2005. ENCONTRO ANUAL DA ANPAD, 29., Brasília, DF, 2005 Anais... Brasília (DF): ANPAD, 2005.

AVElar, A. Os desafios das empresas familiares. Estado de Minas, Belo Horizonte, p. 5, 16 ago. 1998. (Caderno de Economia)

BARDIN, L. Análise de conteúdo. Lisboa: Edições 70, 1988. 225p.

BRONZO, M.; HONÓRIO, L. O institucionalismo e a abordagem das interações estratégicas da firma. RAE Eletrônica, São Paulo, v. 4, n. 1, p. 1-18, 2005. Disponível em: < http://www.rae.com.br/eletronica/index.cfm $>$. Acesso em: 17 nov. 2005.

CHANDLER, A.D. Strategy and structure. Massachusetts: MIT Press, 1976.

CORREA, H. L.; GIANESI, I. G. N. Just in time, MRP e OPT: um enfoque estratégico. São Paulo: Atlas, 1996.

DIAS, M. A. Administração de materiais: princípios, conceitos e gestão. São Paulo: Atlas, 2005.

EDEN, C.; HUXHAM, C. Pesquisa-ação no estudo das organizações. In: CLEGG, R. S. et al. (Org.). Handbook de Estudos Organizacionais reflexões e novas direções. São Paulo: Atlas, 2001. V. II, p. 93-134.

FLEURY. P. F.; LAVALLE, C. Avaliação do Serviço de Distribuição Física: A Relação entre a Indústria de Bens de Consumo e o Comércio Atacadista e Varejista. Centro de Estudos em Logística (CEL)/COPPEAD/UFRJ. 
Thiago Duarte Pimentel • Alexandre de Pádua Carrieri • Alfredo Rodrigues Leite da Silva

Fórum de artigos publicados sobre Logística, 1997. Disponível em: <htpp:// www.cel.coppead.ufrj.br/>. Acesso em: 27 jun. 2006.

HIJJAR, M. F. et al. Evolução do desempenho logístico das indústrias de bens de consumo: uma análise sob a perspectiva do varejista. Centro de Estudos em Logística (CEL)/COPPEAD/UFRJ. Fórum de artigos publicados sobre Logística, 2003. Disponível em: <htpp://www.cel.coppead.ufrj.br/>. Acesso em: 27 jun. 2006.

\section{LAMBERT, D.; STOCK, J.R. Administração estratégica da logística} empresarial. São Paulo: Vantine Consultoria, 1988.

LIMA, M. S.; PIMENTEL, T. D.; CARRIERI, A. de P. Identificando o ponto de equilíbrio entre flexibilidade total e planejamento estático na produção de uma empresa manufatureira do setor de alimentos. In: SIMPÓSIO DE ADMINISTRAÇÃO DA PRODUÇÃO, LOGÍSTICA E OPERAÇÕES INTERNACIONAIS (SIMPOI), 9. 2006. São Paulo, Anais... São Paulo, Escola de Administração de Empresas de São Paulo da Fundação Getulio Vargas (FGV-EAESP), 2006. p. 1-15.

LUZ, T. R. da. TELEMAR-MINAS: competências que marcam a diferença. 2001. 307f. Tese (Doutorado em Administração) - Universidade Federal de Minas Gerais/UFMG. Belo Horizonte, 2001.

PERROW, C. Análise organizacional: um enfoque sociológico. São Paulo: Atlas, 1972.

PORTER, M. E. Vantagem competitiva: criando e sustentando um desempenho superior. Rio de Janeiro: Campus, 1990.

SIMON, H. Comportamento administrativo. Rio de Janeiro: FGV, 1965.

SKINNER, W. Manufacturing: the missing link in corporate strategy. Harvard Business Rewiew, Boston, p. 136-144, may/june 1969.

THIOllENT, M. Metodologia de Pesquisa-ação. São Paulo: Cortez, 1988.

TRIVIÑOS, A. R. S. Introdução a pesquisa em ciências sociais: pesquisa qualitativa em educação. São Paulo: Atlas, 1987.

VERGARA, S. C. Métodos de pesquisa em administração. São Paulo: Atlas, 2005. 
Posicionamento logístico com base nas estratégias de produção em micro-organizações familiares: um estudo de caso..

WANKE, P. Estratégia de posicionamento logístico: conceitos, implicações e análise da realidade brasileira. Centro de Estudos em Logística (CEL)/ COPPEAD/UFRJ. Fórum de artigos publicados sobre Logística, 2001. Disponível em: <htpp://www.cel.coppead.ufrj.br/>. Acesso em: 27 jun. 2006.

YIN, R. K. Case study research: design and methods. Beverly Hills: Sage, 2001. 